\title{
The Three Delay Model as Framework to Assess the Burden of Maternal Deaths in the Urban District of Kitwe, Zambia
}

\author{
Article by Elvis Chipili \\ Ph.D in Public Health, Texila American University, Zambia \\ E-mail: Mpunduchipili@Gmail.Com
}

\begin{abstract}
In Zambia, it is estimated that in excess of 398 women every year die from pregnancy related complications out of every 100,000 live births. The lifetime risk of a woman dying from a pregnancy related complication is 1: 20. The largest contributor to this high number of maternal deaths from the national level perspective has long been considered to be the delay in deciding to seek maternal and obstetrical care at both household and community levels with very little attempts to explore on extent to which the third delay factors have contributed to the high numbers of maternal deaths that have continued to occur un averted in facilities serving s referral centres. This study therefore provided an assessment framework based on the Three Delay Model to explore and assess how the third delay was impacting on the current burden of maternal mortality in an urban setting of Kitwe District of Zambia.

Method: The study was prospective cross-sectional descriptive study involving case file review of maternal deaths that occurred in the delivery facilities of Kitwe District (Hospital and Clinics). The Study Population included all women that had died from pregnancy related complications in the delivery centres of an urban district (Kitwe) of Zambia in 2014 and 2015. The study investigated 30 maternal deaths (25 reviewed cases and 5 unreviewed cases). Data was collected using an adapted 2004 WHO tool: Beyond the Numbers: Reviewing maternal deaths and complications to make pregnancy safer and the Country's Ministry of Health document: 'Beyond the Numbers; Maternal Death Review Forms.

Results: The study revealed majority (56\%) came from the low density areas within the age range of 25-29 years (50\%). Majority (44\%) were referred from health centres within the vicinity hospital, 22\% accessed the facilities using their own means of transport. Referral response was poor with 50\% of the deceased being evacuated after 3 hours following decision to transfer them from the attending local clinic. Most mothers (55\%) came into the facility in a fully conscious state with normal vital signs. Haemorrhage following delivery $(\mathrm{PPH})$ was the leading cause involving $44 \%$ of the diseased, followed by hypertensive disorders including eclamptic fits. Sepsis following incomplete abortion led to $22 \%$ of deaths with deaths occurring on average of 8hrs following admission to the facility. All attendant staff was skilled birth attendants.

Conclusion: The three Delay Model provides such a frame work to explore and identify different barriers women face in accessing quality, timely and effective maternal health care services needed to prevent such deaths. Using this framework, this study has revealed that the burden of maternal deaths occurring in Kitwe District is mainly due to the factors related to the third delay causes of maternal deaths.
\end{abstract}

\section{Introduction}

There are many interlinking factors which can prevent women and girls from access high quality maternal and family planning care. Recognizing the different barriers women face in achieving the timely and effective medical care needed to prevent deaths occurring in pregnancy and childbirth should be on top of the agenda for health care systems promoting Safe Motherhood Practices. The three Delay Model provides such a frame work to explore and identify different barriers women face in accessing quality, timely and effective maternal health care services needed to prevent such deaths. The model identifies three groups of factors which may stop women and girls accessing the levels of maternal health care which 
Texila International Journal of Public Health

Volume 4, Issue 4, Dec 2016

they need: delay in making decision to seek care, delay in reaching the care and delay in receiving appropriate and adequate health care $(\mathrm{MoH}, 2010)$. This study will therefore provide an assessment framework based on the Three Delay Model to identify which of these factors are impacting on the current burden of maternal mortality in an urban setting of Kitwe District.

In Zambia, a significant and big burden of women's ill health in the childbearing group is due to pregnancy and child birth related complications. These women are in the productive age group of 15 to 49 years. It is estimated that 398 women every year die from pregnancy related complications out of every 100,000 live births. The lifetime risk of a woman dying from a pregnancy related complication is 1: 20. This means that a pregnant woman in Zambia has a twenty times chance of developing and dying from pregnancy related complication $(\mathrm{MoH}, 2010)$. Over fifty percent of these maternal deaths are attributed to direct causes of postpartum haemorrhage, sepsis, obstructed labour, abortion, and eclampsia. It has been long noted that majority of these women who die from pregnancy related complications die either at home or on their way to the hospital. The largest contributor to this high number of maternal deaths from the national level perspective was considered to be the delay in deciding to seek maternal and obstetrical care at both household and community levels. Whereas some studies have been done to ascertain the impact of the first and second delay on maternal deaths, the search for the third delay studies yielded no results. This is one of the topics that has been under researched $(\mathrm{MoH}, 2010)$.

Kitwe district is located in the Copperbelt Province of Zambia and covers a total of 737 square kilometres. The district has 32 operational health facilities of which 12 are delivery centres (BEmONC) and One Central Hospital providing CEmONC services. The other two hospitals (Wusakile mine and Sinozam) are privately owned. Population profiles are presented in the table below:

Figure 1. Population number and Key indicators:

\begin{tabular}{|l|l|l|}
\hline \multirow{2}{*}{ category } & 2014 \\
\cline { 2 - 3 } & Number & \% of total population \\
\hline Children $0-11$ months & 16,893 & 2.7 \\
\hline$<5$ year & 101,632 & 16.2 \\
\hline $5-14$ years & 168,755 & 27.0 \\
\hline Women 15 - 49 years & 178,208 & 28.5 \\
\hline All Adults 15 years + & 355,278 & 56.8 \\
\hline Total male (All ages) & 311,341 & 49.8 \\
\hline Total female ( all ages) & 324,324 & 50.2 \\
\hline Total Population / 1 & 625,665 & 100 \\
\hline Population growth rate & & 3.0 \\
\hline
\end{tabular}

Source: SCO, 2010 Census population and Housing, Zambia Population and demographic Projection 2011 - 2035

Whereas previous studies have shown that the first and second delays have been implicated in the burden of maternal deaths in the country and in particular the rural setting where communities stay a distant from the health facilities offering delivery services, and accessibility to health care services are a challenge, no research in Zambia has attempted to discover the extent to which the third delay factors have contributed to the high numbers of maternal deaths that have continued to occur un averted in facilities within the vicinities of the communities. For instance the number of maternal deaths in Kitwe district have shown an upward trend in the past three years with 2015 recording the highest number. Most of these cases occur at Kitwe Central Hospital, the districts only Government owned health facility.

The figure figures below provides a picture of the delivery care in Kitwe. 
Figure 2. Availability of emergency maternal obstetrical Care

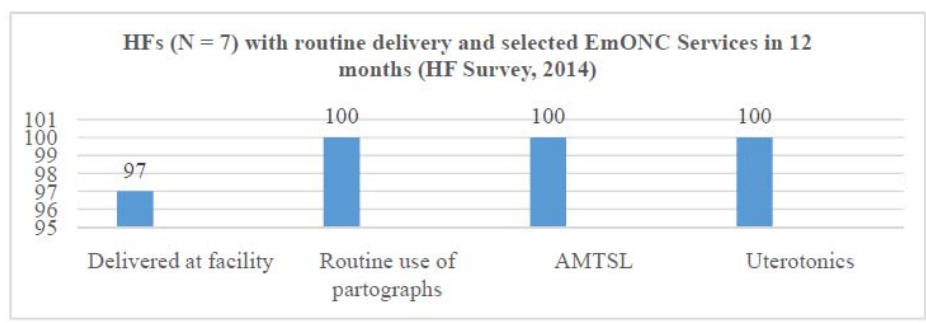

Figure 3. selected determinants

\begin{tabular}{|c|c|}
\hline Selected Determinants & Kitwe District \\
\hline \multicolumn{2}{|l|}{ Supply side (HF survey, 2014) } \\
\hline HFs with $\geq 1$ AMTSL trained HCWs & $70 \%(\mathrm{~N}=10)$ \\
\hline HFs with Magnesium Sulphate & $29 \%(\mathrm{~N}=7)$ \\
\hline HFs with Oxytocin & $100 \%(\mathrm{~N}=7)$ \\
\hline HFs with mothers' waiting shelters & $0 \%(\mathrm{~N}=7)$ \\
\hline \multicolumn{2}{|l|}{ Demand Side (HH survey-LQAS, 2014) } \\
\hline Mothers who live within $1 \mathrm{hr}$ walking distance from HF & $86 \%$ \\
\hline Mothers birth related complications during delivery & $11 \%$ \\
\hline Satisfied with delivery service & $17 \%$ \\
\hline Perception on birth preparedness & $84 \%$ \\
\hline
\end{tabular}

Household Survey - Lot Quality Assurance Sampling, 2014 


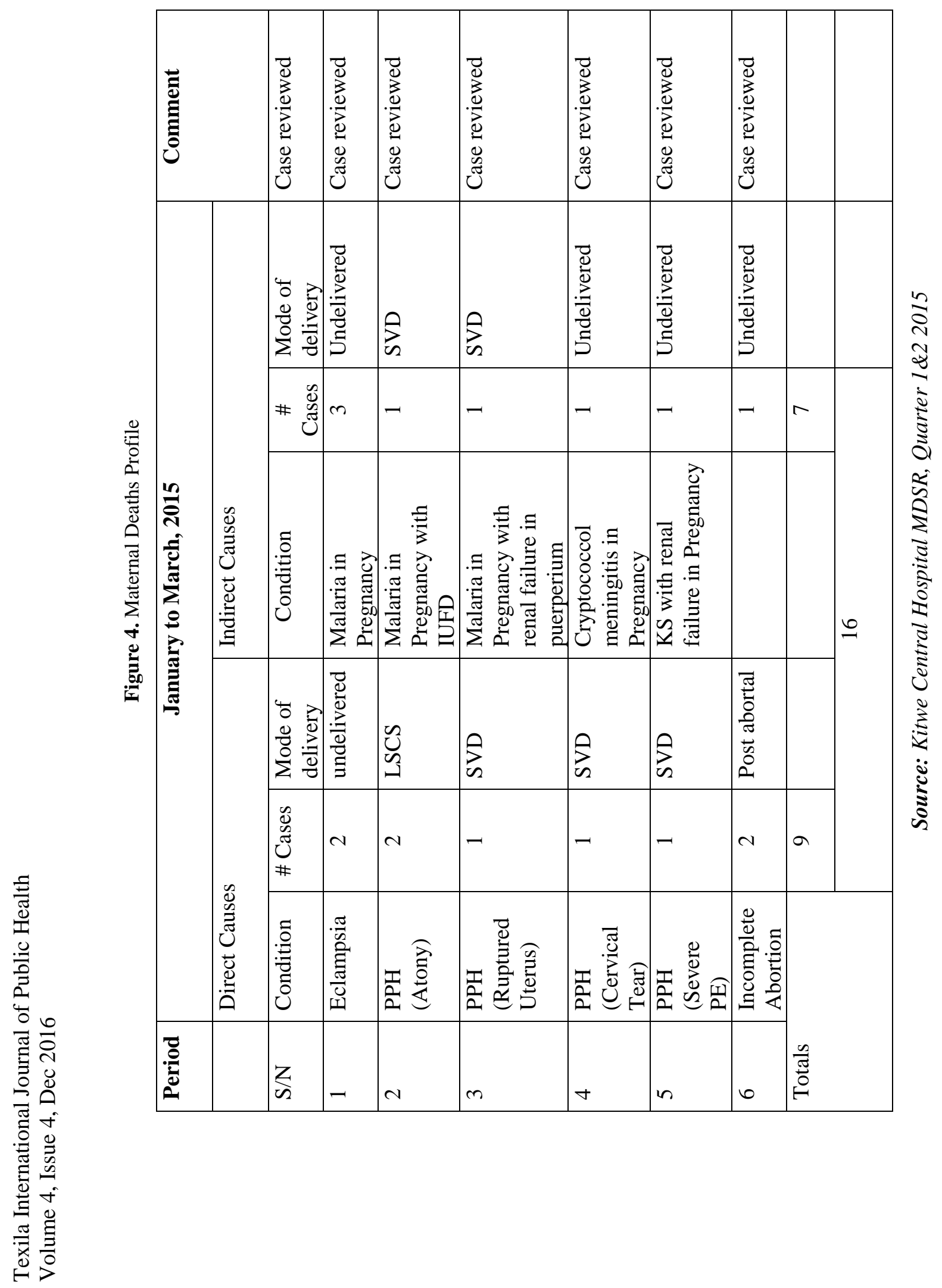




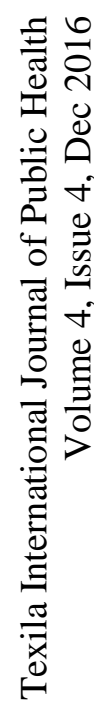

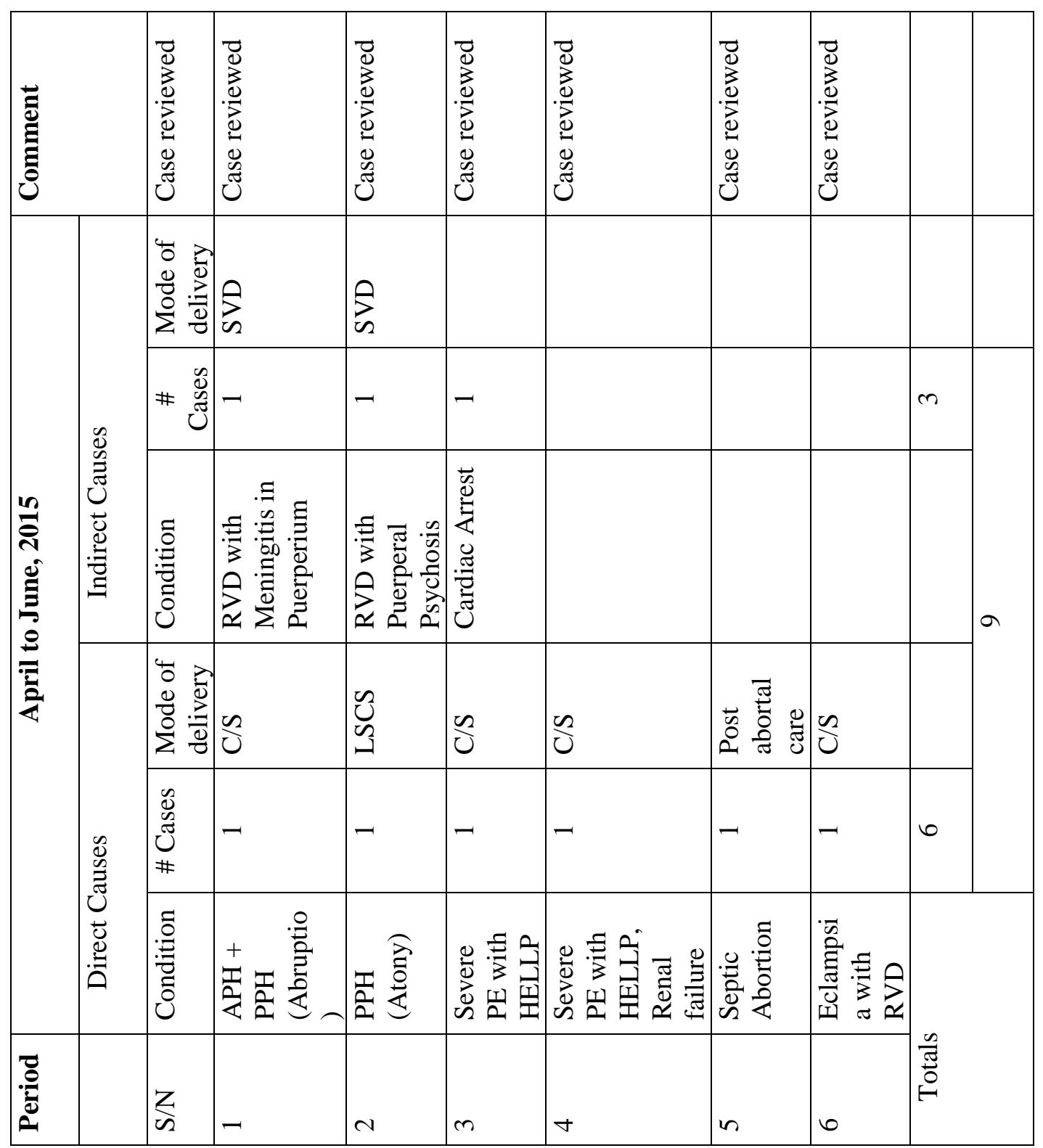




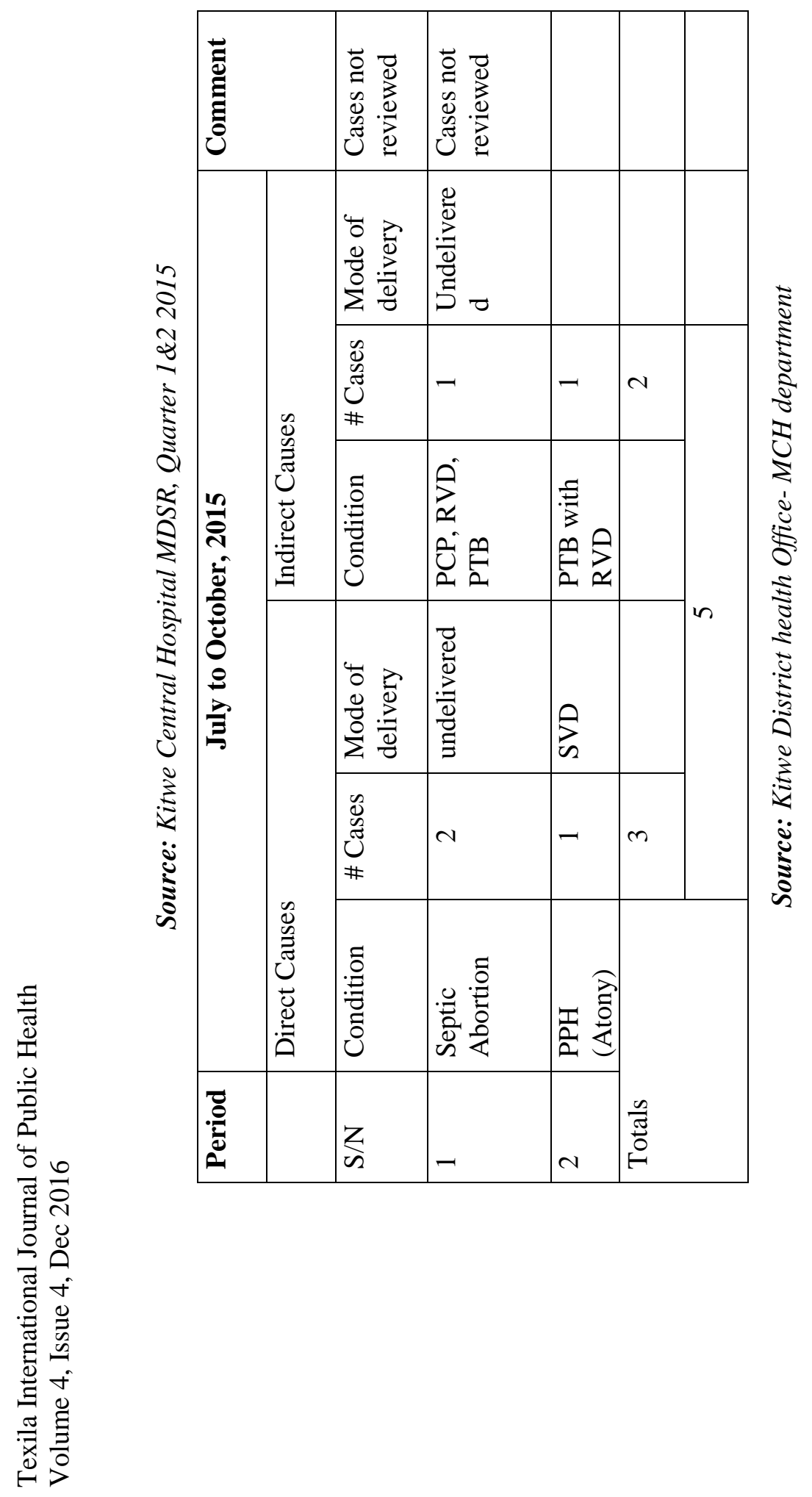


It was scope of this study to apply the Three Delay Model to identify which of the three delays is significantly impacting on the current burden of maternal mortality in an urban setting of Kitwe District.

\section{Objectives}

\section{Main objective}

The main objective of the study was to determine and describe the type of delay commonly contributing to the burden of maternal deaths in Kitwe District.

\section{Specific objectives}

1. To determine the types of delay that commonly contributed to maternal deaths of pregnant women referred and admitted to Kitwe district delivery facilities.

2. To describe the characteristics of women (demographic and pregnancy related) that died from pregnancy complications amongst women admitted to Kitwe district delivery facilities

3. To assess the timing and adequacy of treatment offered to victims of maternal deaths in the admitting delivery facilities of Kitwe District

4. To determine the inpatient duration of stay of maternal death victims

5. To determine the category of staff (Skilled or unskilled) that provided delivery care services to victims of maternal deaths.

\section{Study design}

\section{Methodology}

The study was prospective cross-sectional descriptive study involving case file review of maternal deaths that occurred in the delivery facilities of Kitwe District (Hospital and Clinics). The deaths occurred and were reported by the facilities they occurred from to the District Health Office and reviewed by District Maternal Death Surveillance and Response (MDSR) Committee for all the four quarters in 2014 and three quarters in 2015.

\section{Research setting}

There are twelve health centers in Kitwe, in addition to Kitwe Central Hospital, that provide delivery care services. All of these delivery centres have trained midwives that provide twenty four hour labour and delivery services. However, all the twelve delivery centers refer patients with pregnancy problems (antenatal, intrapartum or puerperal) to Kitwe Central Hospital which has 24 hour anaesthetic cover for the operating theatres and on-site blood transfusion availability throughout the year.

\section{Study Population}

Included all women that had died from pregnancy related complications in the delivery centres of Kitwe and that met the definition of maternal death including cases referred to Kitwe central Hospital from surrounding districts.

\section{Sampling technique}

Owing to the small number of cases, all cases were considered and included in the study.

\section{Sample Size}

Consisted all maternal cases recorded in the three quarters in 2015 and one month in the fourth quarter of the same year. Each quarter being 3 months period. The study sample therefore consisted only of maternal deaths related to direct causes of maternal deaths of 25 reviewed cases and 5 unreviewed cases. 
Texila International Journal of Public Health

Volume 4, Issue 4, Dec 2016

\section{Research instruments}

The study employed the use of an adapted data collection tool which was used for the abstraction of details (See appendix). The data collection tool was based on the WHO document: Beyond the Numbers: Reviewing maternal deaths and complications to make pregnancy safer (2004). In the Ministry of Health document: 'Beyond the Numbers; Maternal Death Review Forms; Community Data Collection Instruments’ was also used (MOH 2005).

\section{Data analysis}

Data was tabulated as simple frequency distributions using appropriate class divisions when more than 2 variables were involved (e.g. age 15-19, 20-24 years etc). Although this was a descriptive study, for illustrative purposes only, comparisons were made of variables (e.g. age, gravidity/parity, blood pressure, days in hospital).

\section{Study Results}

Figure 5 Patients’ demographic characteristics

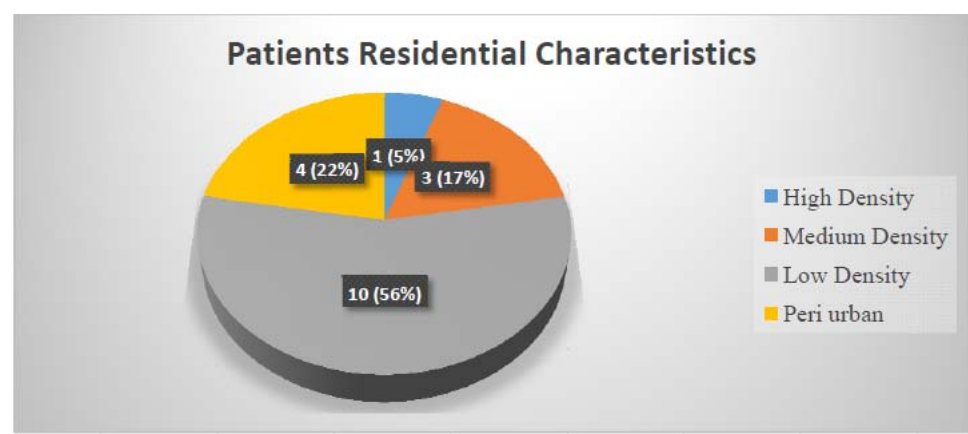

Majority of the deceased clients came from the low density areas (56\%) and $17 \%$ came from the Medium density areas. Only 5\% came from the high density areas with 22\% recorded from the peri urban population.

Figure 6: Age distribution

\begin{tabular}{|l|l|l|l|l|}
\hline S / N & Age range & Frequency & Total & Percentage \\
\hline 1 & $15-19$ years & I & 1 & 6 \\
\hline 2 & $20-24$ years & IIII & 4 & 22 \\
\hline 3 & $25-29$ years & IIIII IIIII & 9 & 50 \\
\hline 4 & $30-34$ years & IIIII II & 4 & 22 \\
\hline 5 & 35 and above & & & \\
\hline
\end{tabular}

Majority of the deceased mothers were from the rage range of 25-29 years (9), closely followed by $20-24$ years range. In the third category were the mothers from the $30-34$ years. Only one case (6\%) was recorded from the age range 15 - 19yrs and no death was recorded in the age arrange 35 - 45yrs old. 
Figure 7. Referral status to health facility

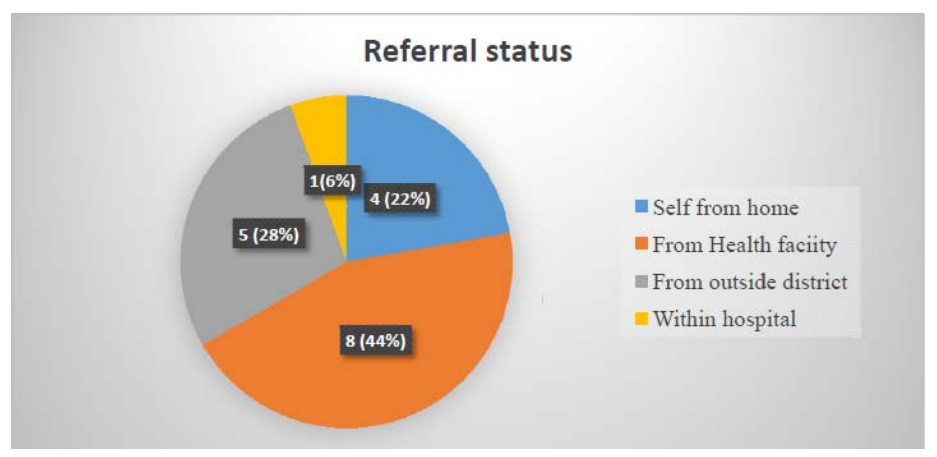

Eight (44\%) out of 18 deceased mothers were referred from the local health facilities to the Central hospital for further management using the institutional ambulances. Five (28\%) were referred from the institutions outside Kitwe district by ambulances from their respectful referring institutions, Four (22\%) accessed the facilities using their own means of transport whilst only 1 client (6\%) was already in the hospital admission wards when the death occurred.

Figure 8. Referral response:

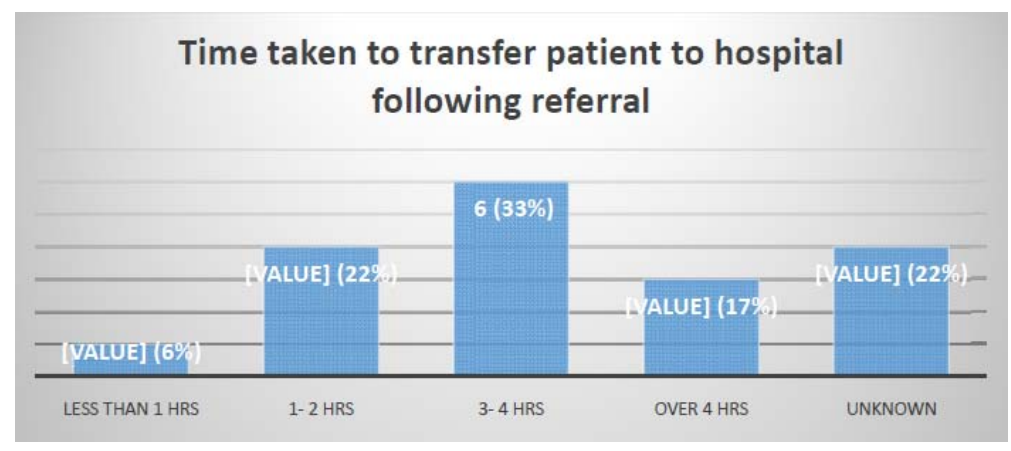

Majority of mothers (over 50\%) were only evacuated to the hospital for further attention by specialists after 3 hours following decision to transfer them from the attending local clinic. $22 \%$ were referred within $1-2$ hours following decision to evacuate them whilst another $22 \%$ of mothers times of referral were not indicated on the case sheets.

Figure 9. Condition of mothers on admission

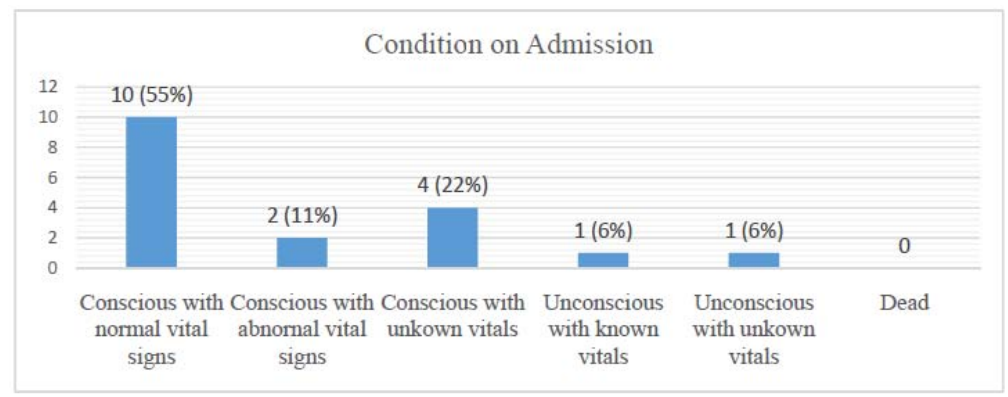

Majority of clients (55\%) came into the facility in a fully conscious state with normal vital signs recorded at admission. Only two cases (11\%) had a record of being conscious with abnormal vital signs (BP and temperature) and no one was brought into the facility already dead. 
Texila International Journal of Public Health

Volume 4, Issue 4, Dec 2016

Figure 10. Diagnosis

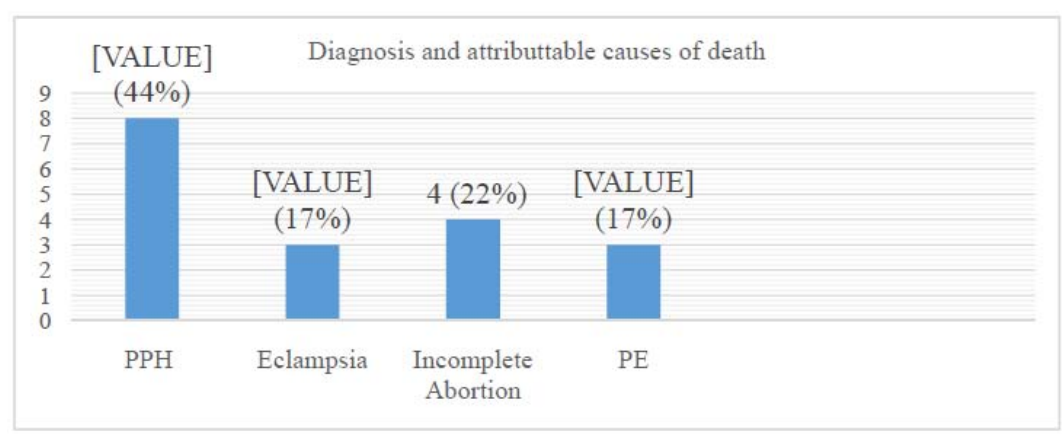

Haemorrhage following delivery (PPH) was the leading cause at $44 \%$, followed by hypertensive disorders including eclamptic fits causing 34 deaths whilst sepsis following incomplete abortion led to $22 \%$ of deaths.

Figure 11. Length of stay in facility

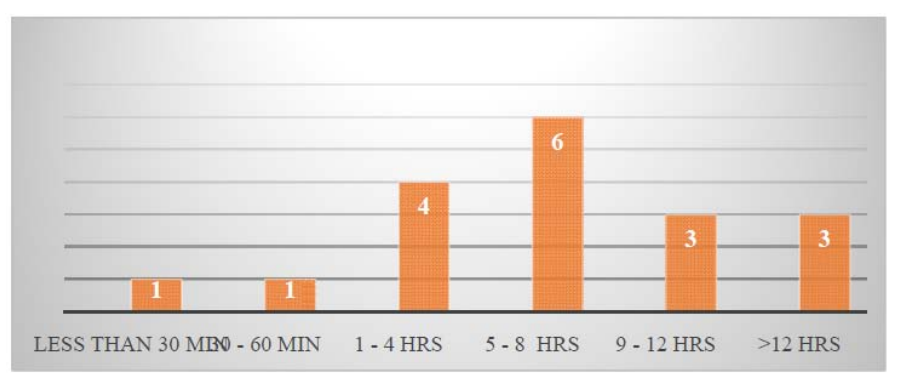

Nine of the mother died between 5 to 12 hours following admission, 3 died after more than 12 hours of hospital stay whilst 4 mothers died within the $1-4$ hours after admission. Only two mothers died less than an hour from admission.

Figure 12. Category of birth attendant

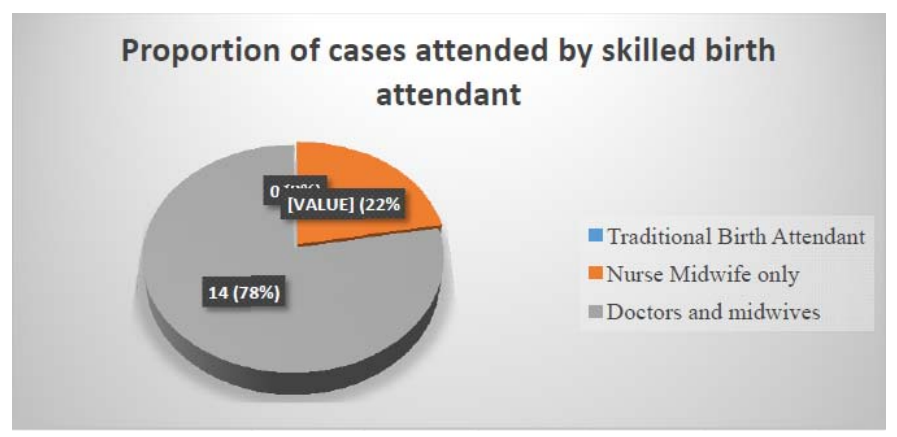

All the cases were attended to by skilled birth attendants (midwives and Doctors). No case was attended to by traditional birth attendants. All the 18 cases were attended to by midwives; $22 \%$ by midwives only, and the rest of the cases $(78 \%)$ were on admission attended to by midwives before referring them to Doctors for surgical interventions.

\section{Discussion}

The study established that all the burden of maternal deaths occurring and being recorded at Kitwe Central Hospital could be classified as those belonging to the third delay of maternal. Under this model, the patient or the mother has managed to reach the health care in time but for some reasons she fails to receive appropriate treatment (care). Failure to receive appropriate care could be due to service inadequate (shortage of staff, inadequate equipment and supplies, absence of service), could also be due delays by poor staff attitude, incompetence, oversight and simply negligence. This finding is in contrast with the some studies conducted in the country that have suggested that most of maternal deaths occur either 
at home or on the way to hospital due to poor health seeking behaviour and distance to health facility (MoH, 2010). In terms of distance to health facility, Kitwe is an urban mining town and most of the residential areas are within an hour's walk to the nearest health facility $(\mathrm{MoH}$, 2014). Most patients therefore easily reach the health facilities by walking or by privately owned cars (minibuses / Taxis). Once at the facility (delivery centre) pregnancy related complications are referred to hospital (Kitwe Central Hospital).

In this study, majority of the women that suffered maternal death were aged between 25 29 years and came from low density areas of the township. All the mothers were referred from facilities within Kitwe (72\%) and from heath institutions in districts outside Kitwe district (28\%). Further study could be needed to determine if at all there are differences in the way clients are attended to in relations to their social economic statuses at Kitwe Central Hospital. The main mode of transport to the hospital on referral was the ambulance service (72\%) whilst $28 \%$ used privately owned transport. However, there was a considerable lapse of time from the time referral decision was made to the time the ambulance service was provided. Majority were only evacuated after 3 hrs. following referral. This is another delay within the facilities and clients despite being in the facility they can be moved quickly enough to access appropriate treatment. This is an indication of poor referral system. Review of the deceased case records indicated that majority of clients (55\%) presented to the attending facilities whilst walking and in fully conscious state with normal vital signs recorded at admission. A smaller number (11\%) had a record of being conscious with abnormal vital signs (BP and temperature) and none was admitted in an unconscious state or dead. However, most complications were noted upon delivery (PPH) or during the period of labour within the facilities. Complications were noted during the process of labour monitoring or upon admission in those that presented with incomplete abortions by attending midwives. Attending midwives were mandated to refer a patients once noted with complication to Central Hospital. However, this study revealed that most mothers (50\%) due to inadequate ambulance service could only be evacuated to hospital after 3 hours following decision to refer them. In $22 \%$ of those referred, no referral time was indicated on their transfer letters and case sheets. This is a kind of service inadequate. The mothers despite reaching the health care early could not be moved in quick time to reach the next appropriate care. In this way patients were subjected to longer stay at the primary health care facility.

The study also established that upon reaching the central hospital, clients were received and attended to by midwives and doctors. Most reached the Central hospital in conscious and stable conditions and stayed for considerable length of time before meeting their fate. A striking feature was that most mothers (67\%) met their fate after staying for considerable number of hours ( 5 - 12hrs) in the referral centre (hospital) whilst in the hands and care of the skilled birth attendants (midwives and Doctors). Most deaths were due to haemorrhage (PPH) following delivery (44\%) and sepsis following unsafe abortions (22\%). Only two mothers died less than an hour from admission. This is also a matter demanding inquiry considering that fact that both haemorrhage and septic abortion are conditions that are treatable and deaths from such can be avoidable if appropriately handled. It would be of interest to undertake another study to assess the readiness of the Central Hospital to handle emergency obstetrical care cases in terms of skills of staff and service adequacy (equipment, drugs and supplies)

\section{Conclusion}

The three Delay Model provides such a frame work to explore and identify different barriers women face in accessing quality, timely and effective maternal health care services needed to prevent such deaths. The model identifies three groups of factors which may stop women and girls accessing the levels of maternal health care which they need: delay in making decision to seek care, delay in reaching the care and delay in receiving appropriate and adequate health care. Using this framework, this study has revealed that the burden of maternal deaths occurring in Kitwe District is mainly due to the factors related to the third delay causes of maternal deaths. 
Texila International Journal of Public Health

Volume 4, Issue 4, Dec 2016

\section{References}

[1] Central Statistics Office (2010) Zambia Demographic and health Survey. Lusaka. Government Printers

[2] Kitwe Central Hospital (2015) Health information management system; Maternal death and surveillance Report. Kitwe Central Hospital.

[3] Ministry of Health (2010) Campaign for Accelerated Reduction of Maternal Mortality in Africa. Lusaka. Ministry of Health

[4] Ministry of Health (2014) LOT quality Assurance Sampling; facility and household Baseline Study. Lusaka. Ministry of Health.

[5] World Health Organization (2004). Beyond the numbers: Reviewing Maternal Deaths and Complications to make pregnancy safer. Geneva. World Health Organization. 